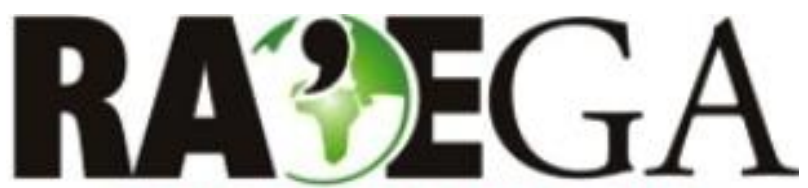

O ESPACYO GEOGRÁFICO EM ANÁLISE

\title{
ANÁLISE SEDIMENTAR E GEOMORFOLÓGICA PARA COMPREENSÃO DA DINÂMICA FLUVIAL LOCAL EM AMBIENTE DE PLANÍCIE COSTEIRA NA REGIÃO NORTE DE SANTA CATARINA
}

\section{SEDIMENTARY AND GEOMORPHOLOGICAL ANALYSIS FOR COMPREHENSION OF LOCAL FLUVIAL DYNAMICS IN COASTAL PLAIN ENVIRONMENT IN NORTHERN SANTA CATARINA STATE}

\author{
Renata Floriano da Cunha ${ }^{1}$, Orestes Jarentchuk Junior ${ }^{2}$, Fabiano Antonio de Oliveira ${ }^{3}$
}

RESUMO

Este trabalho tem como finalidade a caracterização estratigráfica de dois perfis de margem no trecho de planície costeira do rio Três Barras, no município de Garuva (SC). O estudo foi realizado a partir da análise da arquitetura sedimentar, de modo a possibilitar melhor compreensão da dinâmica fluvial neste ambiente costeiro do norte catarinense. As amostras coletadas nas margens erosivas foram submetidas a métodos de análises granulométricas para identificação das sequências deposicionais dos dois pontos específicos do curso fluvial. Os pontos de observação e coleta de amostras foram definidos a partir da análise geomorfológica em escala temporal, considerando fases de reconformação do curso hídrico. Os sedimentos que constituem os perfis analisados evidenciam a intercalação de estratos arenosos com sedimentos pelíticos a montante, ao passo que a jusante há predominância de sedimentos arenosos mais grossos. A variação da assinatura granulométrica ao longo das margens analisadas revela uma possível relação com ciclicidade de eventos de maior e menor energia, fator que possui grande influência na dinâmica fluvial natural e que atualmente são intensificados por importantes intervenções antrópicas.

Palavras-chave: Rio Três Barras; Quaternário; sedimentologia

\section{ABSTRACT}

This work has the purpose of a stratigraphic characterization of two margin profiles of a coastal plain sector of the Três Barras river, municipality of Garuva (SC). The study was based on sedimentary architecture analysis to allow a better understanding of river dynamics in this coastal environment of northern Santa Catarina. Samples collected on the erosive margins were submitted to grain size analysis methods to understand the depositional sequences of the two specific points in the fluvial course. The observation points and sample collection were defined based on geomorphological analysis at a temporal scale, considering reshaping phases of the water course. The sediments that constitute the analyzed profiles show sandy strata with pelitic sediments intercalation upstream, while downstream is observed predominance of coarse sediments. Grain size signature variations along the analyzed banks reveals a possible relation to high and lower energy intercalation, which has a great influence on the natural fluvial dynamics and are intensified by significant anthropic interventions.

Keywords: Três Barras river, Quaternary, sedimentology

Recebido em: 11/08/2016

Aceito em: 20/06/2017

\footnotetext{
${ }^{1}$ Universidade Federal do Paraná, Curitiba/PR, e-mail: floriano.cunha@gmail.com

2 Universidade Federal do Paraná, Curitiba/PR, e-mail: jarentchuk@hotmail.com

${ }^{3}$ Universidade Federal do Paraná, Curitiba/PR, e-mail: foliveira@ufpr.br
} 


\section{ANÁLISE SEDIMENTAR E GEOMORFOLÓGICA PARA COMPREENSÃO DA DINÂMICA FLUVIAL LOCAL EM AMBIENTE DE PLANÍCIE COSTEIRA NA REGIÃO NORTE DE SANTA CATARINA}

\section{INTRODUÇÃO}

Os fluxos hídricos constituem um processo morfogenético dos mais ativos na esculturação da paisagem terrestre e todos os eventos que ocorrem na bacia hidrográfica repercutem direta ou indiretamente nos rios (SUGUIO, 2003). As condições climáticas, a cobertura vegetal e litologia são fatores que controlam a morfogênese das vertentes e, consequentemente, o tipo de carga detrítica a ser fornecida aos rios (CHRISTOFOLETTI, 1980).

Esta carga detrítica, segundo Marçal (2013), está relacionada, além dos processos naturais (morfogenéticos), também a intervenções antrópicas, fatores estes que regem a dinâmica fluvial em relação ao potencial de transporte de sedimento, bem como às mudanças geométricas dos corpos hídricos ao longo do tempo.

Dentre as intervenções antrópicas, destaca-se a modificação dos canais fluviais através de obras de canalização, além de retirada de material sedimentar por meio de mineração de areia ou dragagens, as quais trazem consequências à dinâmica dos rios e bacias hidrográficas relacionadas. Dos resultados destas modificações pode-se enumerar a alteração de velocidade de fluxo, alteração no regime de descarga, incremento da carga sedimentar, aumento da erosão nas margens e perda da sinuosidade dos canais (KELLER, 1978).

Especificamente para este trabalho, objetivou-se caracterizar estratigraficamente a partir da análise da arquitetura sedimentar no trecho do rio Três Barras à jusante da travessia com a rodovia BR-101, com o intuito de fornecer dados para a compreensão da dinâmica fluvial local.

Estudar particularmente este trecho do rio Três Barras se faz importante em consideração a uma possível alteração da dinâmica fluvial local em razão da implantação da travessia da BR-101, devido a obras de canalização em seu trecho mais a montante, além de outras atividades antrópicas como mineração de areia, retirada da mata ciliar e criação de gado. Eventos pluviométricos extremos, alterações da energia do fluxo hídrico e sua descarga líquida devido a estas intervenções, somada a composição sedimentar das margens e leito, acarretam em problemas de cheias periódicas e, consequentemente, perdas materiais.

O trabalho foi desenvolvido a partir da análise geomorfológica em escala temporal, considerando fases de reconformação do curso, em conjunto com análise sedimentar para compreensão da história deposicional em dois pontos específicos do curso fluvial.

\section{MATERIAL E MÉTODOS}

\subsection{CARACTERIZAÇÃO DA ÁREA DE ESTUDO}

O rio Três Barras está localizado no município de Garuva, na parte nordeste do estado de Santa Catarina (Figura 1). 
CUNHA,R.F., JARENTCHUK JUNIOR,O. OLIVEIRA,F.A.

\section{ANÁLISE SEDIMENTAR E GEOMORFOLÓGICA PARA COMPREENSÃO DA DINÂMICA FLUVIAL LOCAL EM AMBIENTE DE PLANÍCIE COSTEIRA NA REGIÃO NORTE DE SANTA CATARINA}

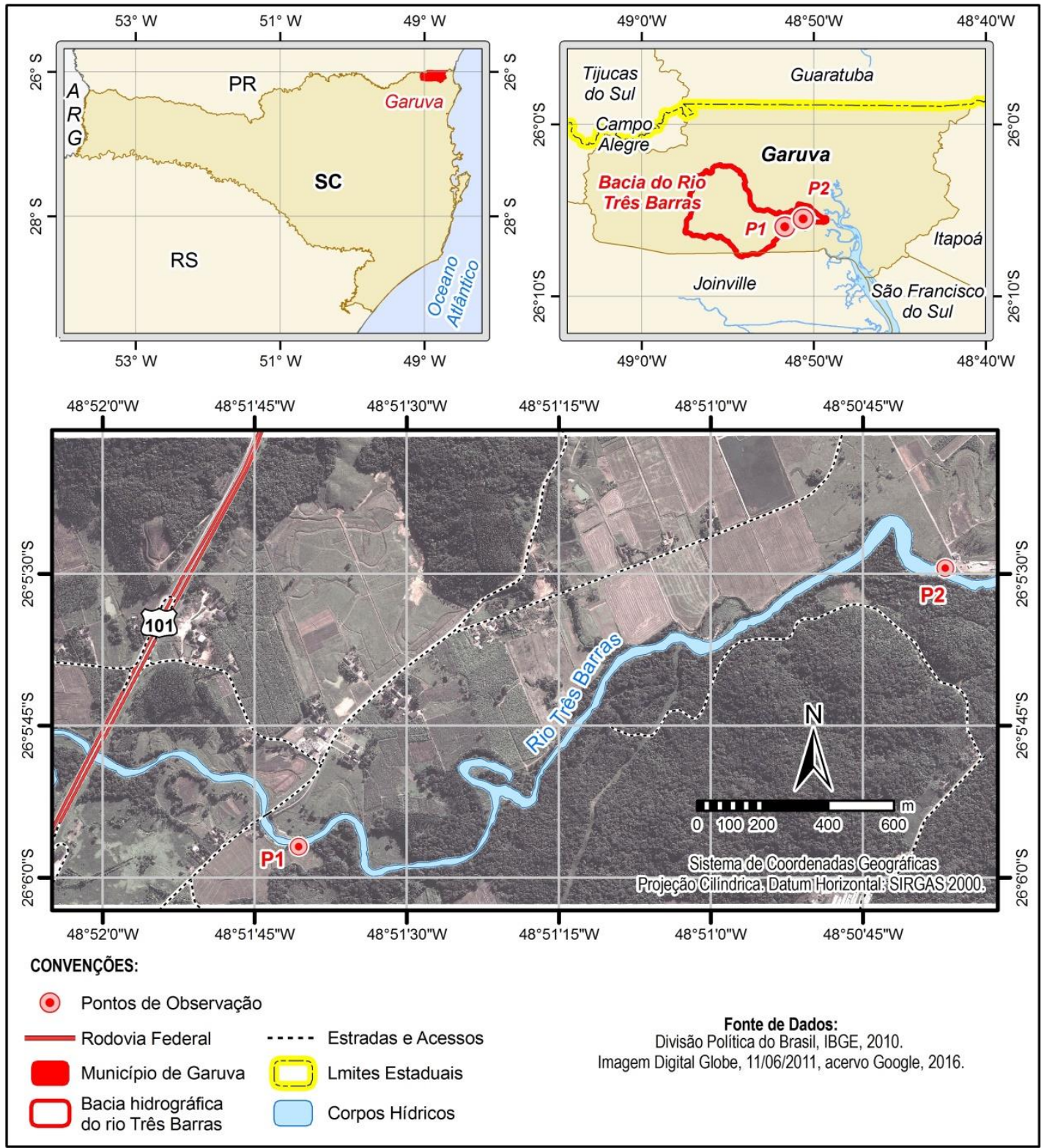

Figura 1 - Localização da área de estudo e perfis de observação.

A bacia hidrográfica do rio Três Barras possui $64,03 \mathrm{~km}^{2}$ e constitui uma significativa área fonte de sedimentos continentais que são transportados para a baía da Babitonga, uma vez que abrange unidades de paisagem distintas. Em seus alto e médio cursos, o rio Três Barras percorre superfícies da Serra do Quiriri, trecho local da Serra do Mar, enquanto seu baixo curso percorre a planície costeira do litoral catarinense, com exutório no canal do Palmital.

O trecho definido para a análise sedimentar e estudo da dinâmica fluvial no rio Três Barras insere-se em seu curso inferior, na planície costeira a Norte de Santa Catarina. Este setor do curso hídrico desenvolve-se em padrão meândrico, onde após a implantação da rodovia federal BR-101 e outras intervenções antrópicas importantes, mudanças significativas em seu percurso são notáveis. Historicamente, a construção de trechos da rodovia entre os municípios catarinenses de Garuva e Florianópolis ocorreu entre os anos de 1958 e 1962, e obras de duplicação no trecho entre Garuva/SC e Curitiba/PR foram executadas entre os anos de 1994 e 1995. 


\section{ANÁLISE SEDIMENTAR E GEOMORFOLÓGICA PARA COMPREENSÃO DA DINÂMICA FLUVIAL LOCAL EM AMBIENTE DE PLANÍCIE COSTEIRA NA REGIÃO NORTE DE SANTA CATARINA}

Essas obras teriam condicionado a reconformação do traçado do rio Três Barras entre os dois pontos estudados, como é possível observar a partir do cartograma da Figura 2. Aventa-se que essa situação ocorreu devido à estrutura de travessia implantada, condicionando a energia do curso hídrico e impondo a reconformação de seu percurso à jusante. Cabe ressaltar que não há informações a respeito das descargas líquida e sólida do curso hídrico antes e após execução das obras de implantação da rodovia, de maneira que a interpretação acerca do acréscimo na velocidade do fluxo hídrico se dá a partir de análise de fotografias aéreas e imagens de sensores remotos.

Foram definidos, a partir de análise geomorfológica do percurso do leito do curso hídrico em escala temporal, dois pontos de observação e coleta de amostras para a caracterização granulométrica. 
CUNHA,R.F., JARENTCHUK JUNIOR,O. OLIVEIRA,F.A.

\section{ANÁLISE SEDIMENTAR E GEOMORFOLÓGICA PARA COMPREENSÃO DA DINÂMICA FLUVIAL LOCAL EM AMBIENTE DE PLANÍCIE COSTEIRA NA REGIÃO NORTE DE SANTA CATARINA}

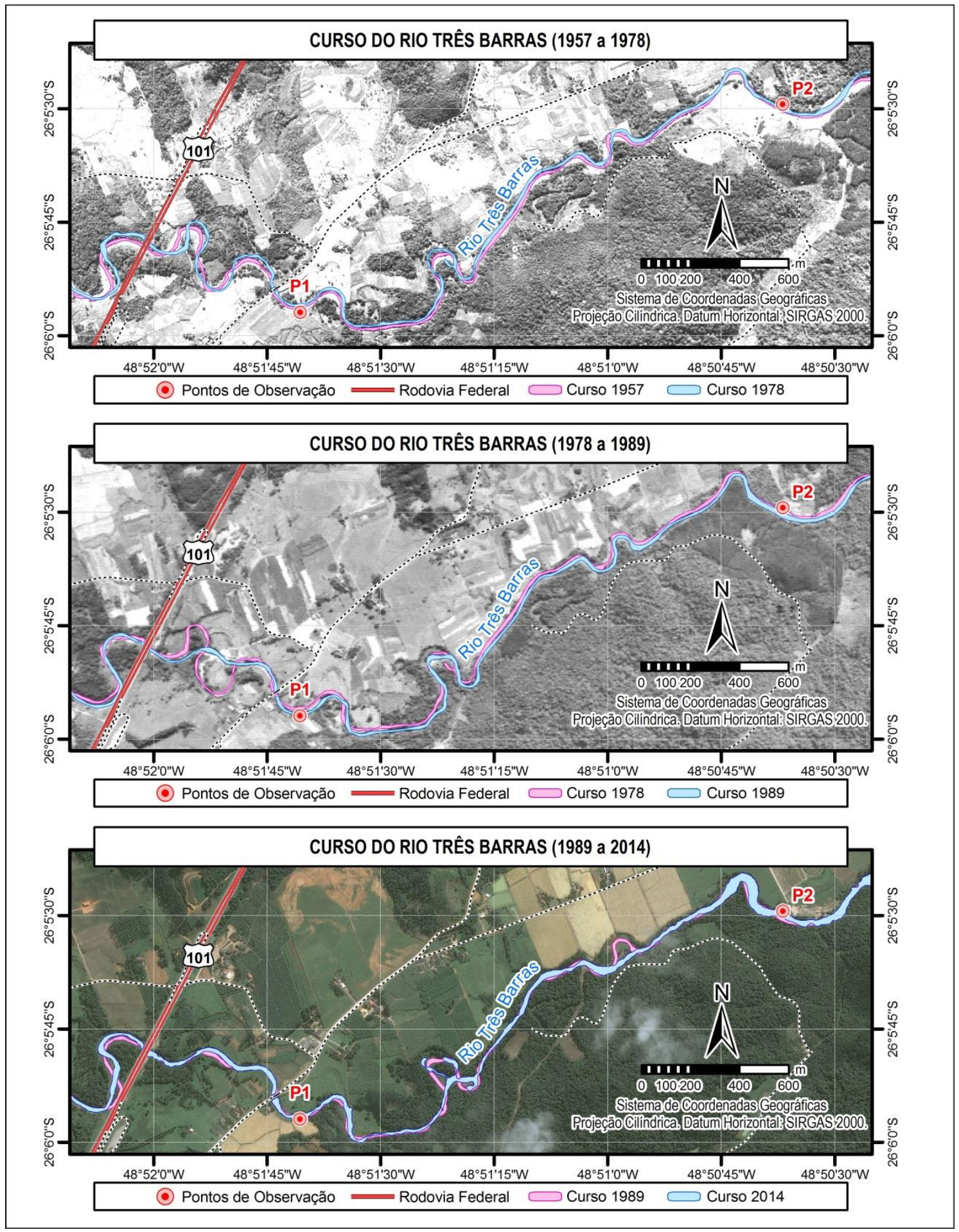

Figura 2 - Fases de reconformação do traçado de trecho do rio Três Barras.

Segundo o cartograma apresentado pela Figura 2, notam-se três fases de reconformação do rio Três Barras, cuja análise orientou a definição dos pontos de observação e coleta sedimentar. Ressalta-se que, devido às dificuldades de acesso, pontos adicionais intermediários de observação (entre os pontos P01 e P02) não foram avaliados.

A primeira fase refere-se à situação anterior à construção da rodovia e sua estrutura de travessia (1957) e se estende por aproximadamente 20 anos (até 1978). Nota-se 


\section{ANÁLISE SEDIMENTAR E GEOMORFOLÓGICA PARA COMPREENSÃO DA DINÂMICA FLUVIAL LOCAL EM AMBIENTE DE PLANÍCIE COSTEIRA NA REGIÃO NORTE DE SANTA CATARINA}

que entre a travessia e o ponto de observação P01, ao longo desse período, ocorreu uma significativa alteração do curso natural do rio, com processos erosivos das margens bastante acentuados.

$\mathrm{Na}$ segunda fase, período correspondente às duas décadas subsequentes (entre 1978 e 1989), no mesmo trecho entre a travessia da rodovia e o ponto de observação P01, uma grande alteração ocorre condicionada pelo acréscimo de energia ao fluxo hídrico, forçando a reconformação do percurso com abandono de meandros.

Na última fase, período correspondente a 35 anos (entre 1989 e 2014), o trecho entre a travessia da BR-101 e o ponto de observação P01 permanece estável em seu leito. Entretanto, alterações significativas com a reconformação do canal são notórias no trecho entre os pontos de observação P01 e P02.

\subsection{COLETA E ANÁLISE DE SEDIMENTOS}

As amostras foram coletadas em dois pontos situados junto à margem do rio Três Barras, no seu trecho de planície costeira (Figura 1). Os pontos distam cerca de $3 \mathrm{~km}$ entre si ao longo do trecho do rio e foram escolhidos de forma a abranger maior variação das características granulométricas. A posição do ponto 1 (coordenadas UTM: 713.887 E / 7.111.57 N) apresenta uma situação de maior carga de sedimentos oriundos da Serra do Quiriri e, em escala temporal, está situado em local que sofre forte influência do acréscimo de energia de descarga líquida em razão da implantação da ponte da BR-101. Por sua vez, o ponto 2 (coordenadas UTM: 715.674 E / 7.112.397 N) situa-se em segmento do rio com menor energia de transporte de sedimentos. Assim, para os dois perfis analisados foram coletadas um total de 17 amostras, nove referentes ao Ponto 1 , a montante, cujo perfil possui altura de $6 \mathrm{~m}$, e oito amostras referentes ao Ponto 2 , a jusante, cujo perfil possui altura de $4 \mathrm{~m}$. A espacialização dos pontos de observação é representada nas Figura 1 e 2 . O material foi coletado ao longo de perfis estratigráficos nas margens erosivas do canal fluvial, em zonas core de estratos que apresentam visível distinção de cor e textura.

As amostras foram processadas segundo análises granulométricas tradicionais de peneiramento e pipetagem (Figura 3), assim como através de granulometria a laser, com a finalidade de testar o grau de confiabilidade destes métodos empregados. A realização das análises granulométricas tradicionais foi executada em fases sequenciais, passando por: a) secagem inicial; b) quarteamento c) pesagem inicial; d) pipetagem de sedimentos finos com uso de defloculante (pirofosfato de sódio); e) elutriação; f) secagem de sedimentos grossos; e, por fim, g) peneiramento. Foi adotado ensaio de sedimentação normatizado pela Associação Brasileira de Normas Técnicas (ABNT), na NBR 7181 (1984), para rochas e solos. A classificação granulométrica corresponde à escala phi $(\phi)$ de Krumbein (1934), em que $\phi=-\log _{2} d$, onde $d$ corresponde ao tamanho da partícula em milímetros. 


\section{ANÁLISE SEDIMENTAR E GEOMORFOLÓGICA PARA COMPREENSÃO DA DINÂMICA FLUVIAL LOCAL EM AMBIENTE DE PLANÍCIE COSTEIRA NA REGIÃO NORTE DE SANTA CATARINA}

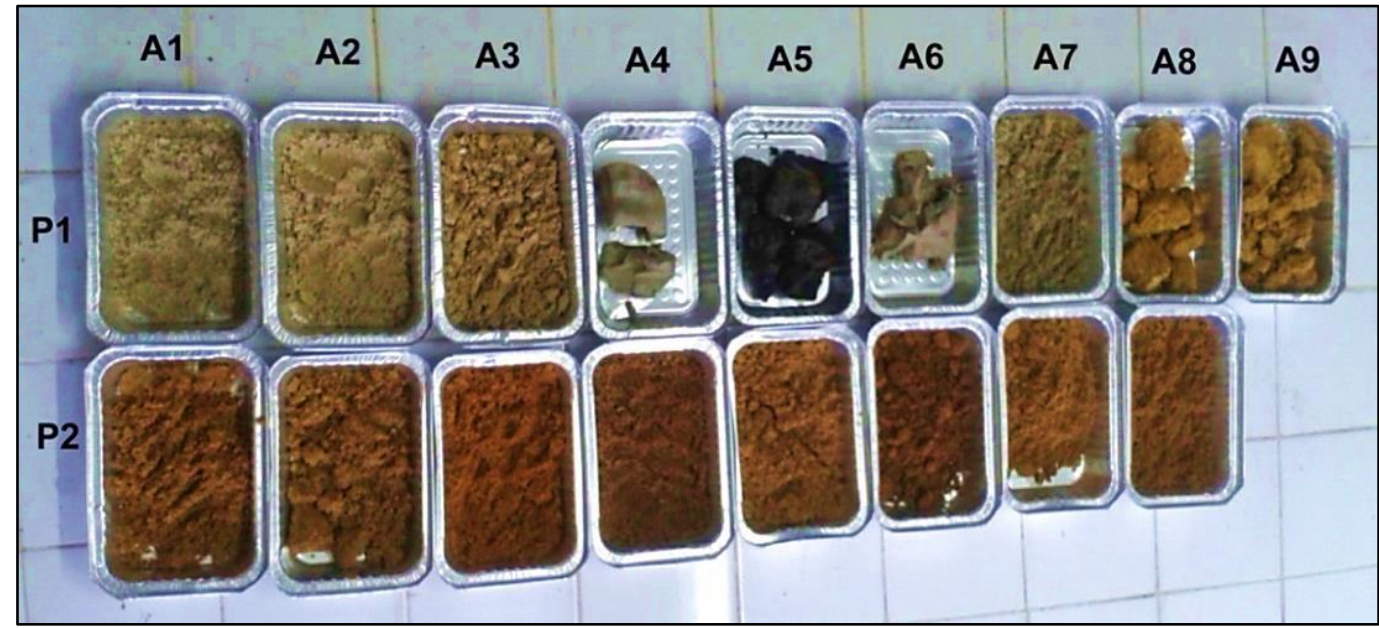

Figura 3 - Amostras sedimentares após secagem.

Os parâmetros considerados na análise estatística foram média, mediana, seleção (desvio padrão), assimetria e curtose. O material retido em cada peneira foi pesado e os parâmetros estatísticos foram calculados segundo as equações propostas por Folk e Ward (1957), com o uso do programa SYSGRAN (CAMARGO, 1999; CAMARGO, 2006). Com exceção da amostra com alto teor de matéria orgânica, a qual foi oxidada por aquecimento com peróxido de hidrogênio, todas as outras amostras foram analisadas no granulômetro a laser (Microtrac - S3500). Para tanto, foram separados 2,0 mg de cada amostra, sem uso de defloculante nas amostras de sedimentos finos, e em triplicata. A análise das propriedades morfológicas dos grãos foi realizada com o uso de lupa de bolso com aumento de 20X, comparando-se os sedimentos com cartas de esfericidade e arredondamento.

\section{RESULTADOS E DISCUSSÃO}

A distribuição das amostras coletadas nos perfis dos pontos 1 e 2 é ilustrada pela figura 4. Os parâmetros estatísticos obtidos para as 17 amostras estão resumidos no quadro 1 , enquanto que a caracterização da morfologia dos sedimentos dos perfis analisados está representada no quadro 2 . 


\section{ANÁLISE SEDIMENTAR E GEOMORFOLÓGICA PARA COMPREENSÃO DA DINÂMICA FLUVIAL LOCAL EM AMBIENTE DE PLANÍCIE COSTEIRA NA REGIÃO NORTE DE SANTA CATARINA}
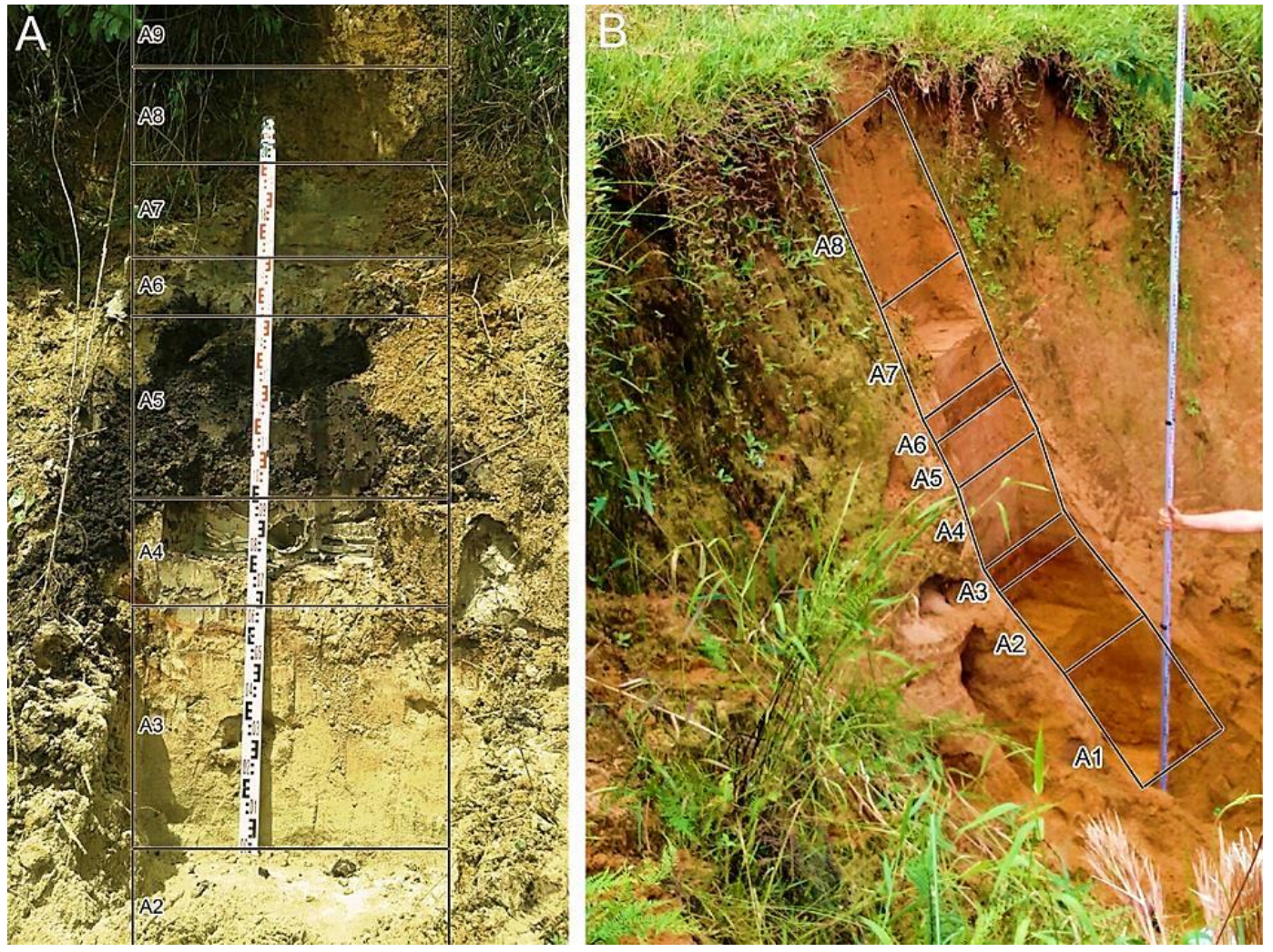

Figura 4 - Identificação dos estratos sedimentares e coletas de amostras para análises granulométricas. (A) perfil 1 (9 amostras); (B) perfil 2 (8 amostras).

Grosso modo, a classificação granulométrica reflete a predominância de tamanhos de partículas em cada estrato dos perfis analisados. Nesse sentido, observa-se que as classes granulométricas variam de areia (-1Ф a
4Ф) a silte e argila (4Ф a >8Ф) no ponto 1 , predominando areias grossa a fina, enquanto que no ponto 2 os sedimentos estão concentrados na classe de tamanho areia (-1Ф a 4Ф), em especial areia grossa (Quadro 1).

Quadro 1 - Parâmetros granulométricos e classificação dos sedimentos dos perfis analisados

\begin{tabular}{|c|c|c|c|c|}
\hline \multicolumn{5}{|c|}{ Perfil 1} \\
\hline Amostra & Classificação & Grau de seleção & Assimetria & Curtose \\
\hline 1 & Areia grossa & Mod. selecionado & Aprox. simétrica & Leptocúrtica \\
\hline 2 & Areia média & Mod. selecionado & Muito negativa & Leptocúrtica \\
\hline 3 & Areia fina & Pobrem. selecionado & Muito positiva & Muito leptocúrtica \\
\hline 4 & Argila grossa & Pobrem. selecionado & Muito negativa & Extrem. Leptocúrtica \\
\hline 5 & Silte fino & Muito pobrem. selecionado & Muito negativa & Muito platicúrtica \\
\hline 6 & Silte fino & Muito pobrem. selecionado & Muito negativa & Extrem. Leptocúrtica \\
\hline 7 & Areia fina & Mod. selecionado & Muito positiva & Mesocúrtica \\
\hline 8 & Argila grossa & Mod. selecionado & Muito negativa & Extrem. Leptocúrtica \\
\hline 9 & Silte grosso & Muito pobrem. selecionado & Muito positiva & Muito platicúrtica \\
\hline \multicolumn{5}{|c|}{ Perfil 2} \\
\hline 1 & Areia grossa & Pobremente selecionado & Muito positiva & Extrem. Leptocúrtica \\
\hline
\end{tabular}


CUNHA,R.F., JARENTCHUK JUNIOR,O. OLIVEIRA,F.A.

\section{ANÁLISE SEDIMENTAR E GEOMORFOLÓGICA PARA COMPREENSÃO DA DINÂMICA FLUVIAL LOCAL EM AMBIENTE DE PLANÍCIE COSTEIRA NA REGIÃO NORTE DE SANTA CATARINA}

\begin{tabular}{|llllll}
2 & Areia grossa & Muito pobrem. selecionado & Muito positiva & Platicúrtica \\
3 & Areia grossa & Mod. selecionado & Aprox. simétrica & Muito leptocúrtica \\
4 & Areia grossa & Mod. selecionado & Negativa & Mesocúrtica \\
5 & Areia média & Pobrem. selecionado & Muito positiva & Muito leptocúrtica \\
6 & Areia fina & Pobrem. selecionado & Muito positiva & Muito leptocúrtica \\
7 & Areia média & Mod. selecionado & Aprox. simétrica & Leptocúrtica \\
8 & Areia fina & Pobrem. selecionado & Muito positiva & Muito leptocúrtica
\end{tabular}

O grau de seleção dos grãos de cada amostra define o desvio padrão da distribuição dos tamanhos das partículas e, com o resultado encontrado (Quadro 1), é possível reforçar a afirmação de que em ambientes fluviais os sedimentos são definidos como pobremente a moderadamente selecionados (MARTINS, 2003).

Em relação à assimetria, nota-se que no perfil 1 (Figuras 5 e 7) ocorrem tanto curvas de distribuição assimétricas negativas com curvas positivas (Quadro 1), sem uma visível associação com a granulometria e grau de seleção dos sedimentos. Ao passo que no perfil 2 (Figuras $6 \mathrm{e}$ 7) há predominância de assimetrias positivas, referindo-se aos estratos com incidência de sedimentos com areias grossa (amostras 1 e 2), média (amostra 5) e fina (amostra 6). Friedman (1961) afirma que os parâmetros texturais dos sedimentos, incluindo as curvas de distribuição, estão relacionados principalmente com o modo de transporte e as condições de energia do meio de transporte.

De acordo com Duane (1964), curvas de assimetria negativa são indicativas de momentos erosivos ou não-deposicionais, as de assimetria positiva constituem momentos de deposição, ao passo que uma mistura dos dois tipos de curvas em um depósito sugere áreas com ambas as características. No caso do perfil 1, a alternância de curvas de distribuição pode indicar a transição de momentos de erosão e deposição, enquanto que no perfil 2, localizado mais a jusante, a ocorrência maior de assimetrias positivas indicam uma condição predominantemente de deposição em uma porção do rio onde a energia do meio diminui.

No que diz respeito à curtose, a distribuição de frequências de grãos em relação ao tamanho nos dois perfis varia de um estrato a outro (Quadro 1; Figuras 5, 6 e 7) ocorrendo com maior frequência, entretanto, entre os graus de concentração mais elevados (curvas leptocúrticas). Isto se dá principalmente devido ao transporte de sedimentos oriundos de um ambiente de maior energia para um ambiente de deposição com menor energia (FOLK e WARD, 1957). Desta forma, a natureza de ambas as distribuições são mantidas, gerando gradiente bimodal que origina um ambiente de seleção média ou baixa, característicos de um ambiente fluvial (Quadro 1). 
CUNHA,R.F., JARENTCHUK JUNIOR,O. OLIVEIRA,F.A.

\section{ANÁLISE SEDIMENTAR E GEOMORFOLÓGICA PARA COMPREENSÃO DA DINÂMICA FLUVIAL LOCAL EM AMBIENTE DE PLANÍCIE COSTEIRA NA REGIÃO NORTE DE SANTA CATARINA}

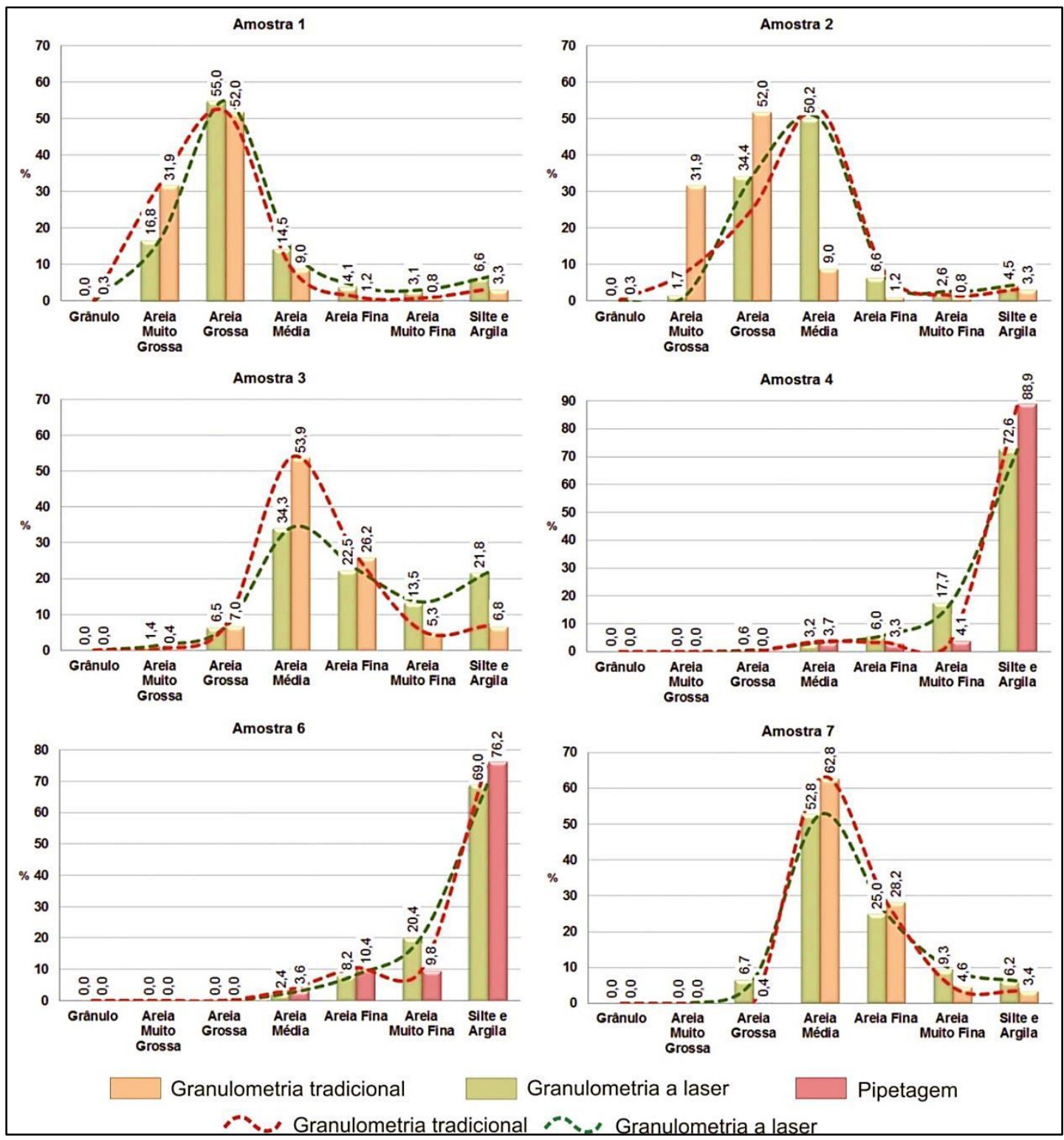

Figura 5 - Distribuição granulométrica no perfil 1 para as amostras 1 a 7, ilustrando a comparação dos resultados a partir de análise granulométrica convencional (curva vermelha) e granulometria a laser (curva verde).

A representação gráfica das curvas de distribuição granulométrica dos resultados obtidos pelos métodos de análise com granulômetro laser e convencional para os pontos de amostragem 1 e 2 (Figuras 5 e 6, respectivamente), permite verificar que existe concordância e coerência dos resultados obtidos por ambos os métodos de análise. 


\section{ANÁLISE SEDIMENTAR E GEOMORFOLÓGICA PARA COMPREENSÃO DA DINÂMICA FLUVIAL LOCAL EM AMBIENTE DE PLANÍCIE COSTEIRA NA REGIÃO NORTE DE SANTA CATARINA}

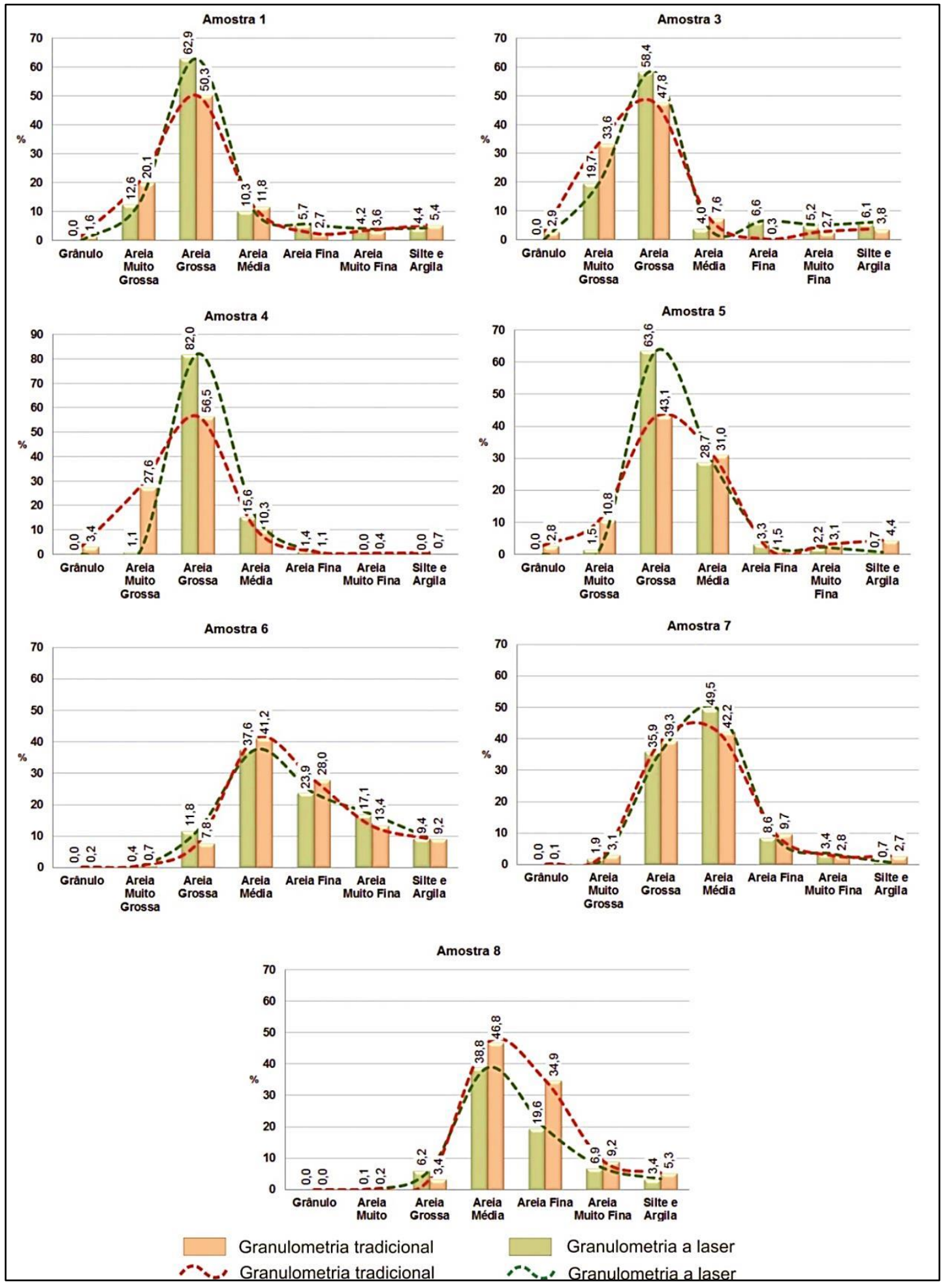

Figura 6 - Distribuição granulométrica no perfil 2 para as amostras 1 a 8, ilustrando a comparação dos resultados a partir de análise granulométrica convencional (curva vermelha) e à granulometria a laser (curva verde).

Entretanto, para as amostras 5, 8 e 9, do ponto de amostragem 1, e amostra 2, do ponto de amostragem 2, apenas os resultados obtidos pelo método de pipetagem são considerados (Figura 7). A amostra 5, em decorrência da grande quantidade de matéria orgânica, não foi 


\section{ANÁLISE SEDIMENTAR E GEOMORFOLÓGICA PARA COMPREENSÃO DA DINÂMICA FLUVIAL LOCAL EM AMBIENTE DE PLANÍCIE COSTEIRA NA REGIÃO NORTE DE SANTA CATARINA}

analisada pelo método de granulometria a laser, exigindo procedimento específico para preparação com peróxido de hidrogênio.

As amostras 8 e 9 do perfil 1 e amostra 2 do perfil 2 demonstraram resultados divergentes entre os métodos tradicional e de granulometria a laser, possivelmente devido à presença de óxidos e hidróxidos de ferro, o que é evidenciado pelas cores amareladas e avermelhadas nos sedimentos. Na análise pela granulometria a laser observou-se um incremento na porcentagem de partículas grossas nestas amostras, possivelmente devido à capacidade destas substâncias de formar agregados. Dessa forma, preferiu-se considerar apenas os resultados obtidos pelo método de pipetagem no qual foi empregado o composto defloculante na preparação das amostras de sedimentos finos (pirofosfato de sódio).

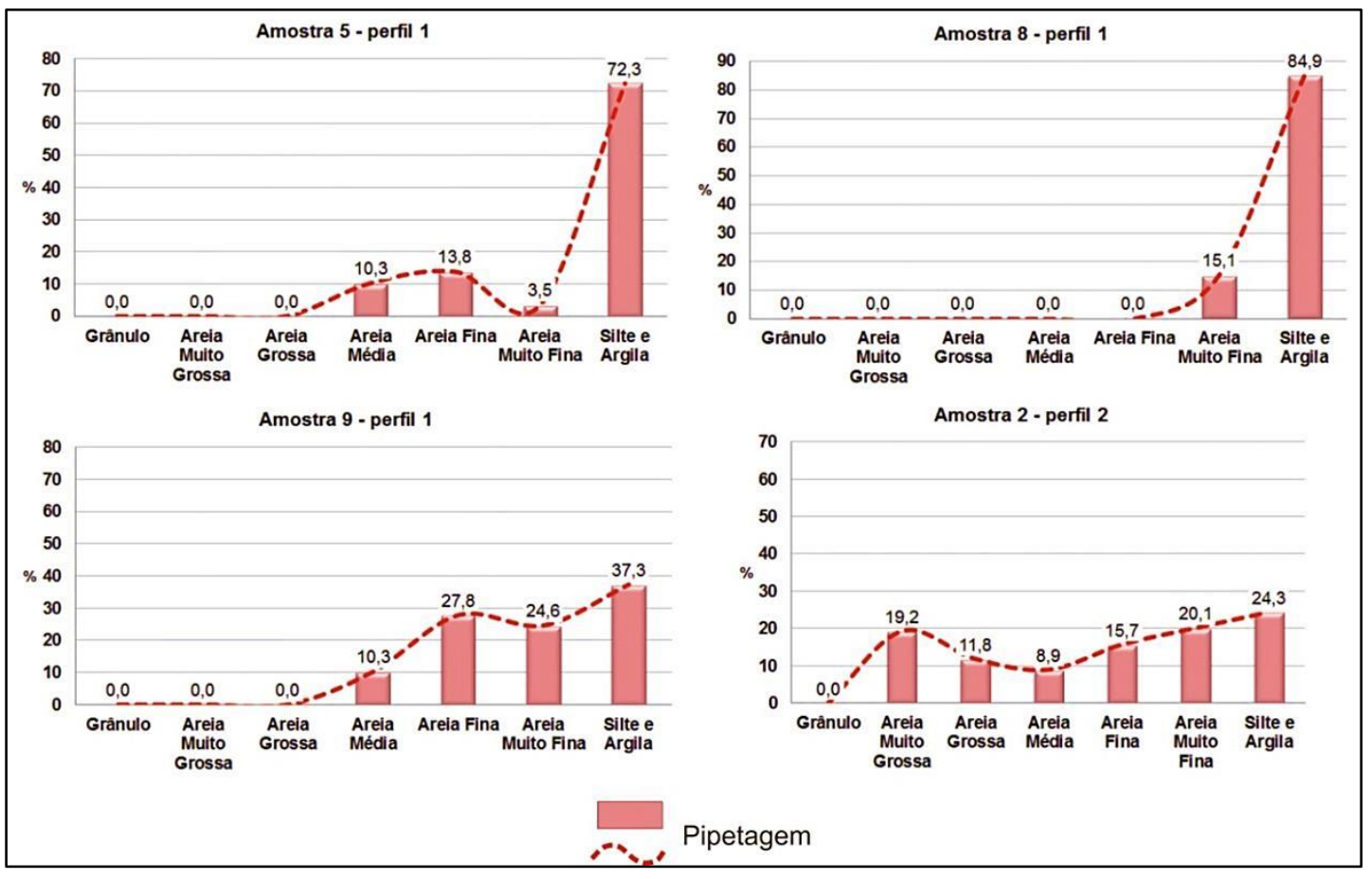

Figura 7 - Distribuição granulométrica para as amostras 5, 8 e 9 (perfil 1) e amostra 2 (perfil 2), especificamente pelo método de pipetagem.

A análise morfoscópica (Quadro 2) demonstrou que o arredondamento dos grãos varia de subanguloso a subarredondado com predominância de partículas de alta esfericidade no perfil 1 e muito anguloso a subarredondado no perfil 2, com predominância de grãos de baixa esfericidade. Observa-se variação de arredondamento e esfericidade dentro de uma mesma amostra, em ambos os perfis, em que as partículas maiores apresentam-se mais arredondadas que as menores. Desta forma, é considerada na caracterização somente a porcentagem predominante.

Esta diferença de arredondamento entre distintas classes granulométricas em uma mesma camada sugere efeitos de abrasão in situ, quando uma partícula vibra no lugar sem movimento a jusante (SCHUMM \& STEVENS, 1973). Com o aumento da velocidade de fluxo, a partícula suspende-se do leito e, por efeito de saltação, move-se a jusante para uma nova posição de estabilidade temporária, podendo, eventualmente, ser fraturada. Durante um fluxo de alta velocidade, a abrasão in situ e fraturamento dos grãos durante a saltação podem ser fatores significativos no arredondamento e redução do tamanho de partículas grossas em rios.

Além da abrasão e fraturamento de sedimentos in situ, deve-se considerar, da mesma 


\section{ANÁLISE SEDIMENTAR E GEOMORFOLÓGICA PARA COMPREENSÃO DA DINÂMICA FLUVIAL LOCAL EM AMBIENTE DE PLANÍCIE COSTEIRA NA REGIÃO NORTE DE SANTA CATARINA}

forma, o input de material de natureza distinta do material de local de deposição em diferentes momentos (DOEGLAS, 1946; SPENCER, 1963), originando uma assembleia textural mista.

As amostras do perfil 1 são constituídas essencialmente de grãos de quartzo e, subordinadamente, feldspatos, ao passo que no perfil 2 observa-se ocorrência de fragmentos de rocha e minerais como feldspatos, minerais máficos e micas (Quadro 2, amostras 2, 4 e 5). A variação textural, com predominância de grãos angulosos e baixa esfericidade, associado à mistura de clastos de diferentes materiais, reforça a hipótese de input de material alóctone no perfil mais a jusante (ponto 2).

Quadro 2 - Caracterização morfológica dos sedimentos analisados dos perfis 1 e 2

\begin{tabular}{|c|c|c|}
\hline \multicolumn{3}{|c|}{ Perfil 1} \\
\hline Amostra & Arredondamento & Esfericidade \\
\hline 1 & subarredondado & alta \\
\hline 2 & subarredondado & alta \\
\hline 3 & subanguloso & alta \\
\hline 4 & \multicolumn{2}{|c|}{ camada argilosa } \\
\hline 5 & \multicolumn{2}{|c|}{ camada com matéria orgânica } \\
\hline 6 & subanguloso & alta \\
\hline 7 & subanguloso & alta \\
\hline 8 & subanguloso & baixa \\
\hline 9 & subanguloso & alta \\
\hline \multicolumn{3}{|c|}{ Perfil 2} \\
\hline 1 & subanguloso & baixa \\
\hline 2 & subanguloso & alta \\
\hline 3 & anguloso & baixa \\
\hline 4 & subanguloso & baixa \\
\hline 5 & subarredondado & baixa \\
\hline 6 & subanguloso & baixa \\
\hline 7 & muito anguloso & baixa \\
\hline 8 & subanguloso & alta \\
\hline
\end{tabular}

No perfil 1, a alternância de estratos de granulometrias grossas e finas sugere ciclicidade bem marcada na intensidade de transporte (Figuras 4a, 8a e 9a). A predominância de sedimentos finos neste perfil, além dos sedimentos apresentarem graus de seleção variando de moderadamente a muito pobremente selecionados, indica que o rio Três Barras, neste ponto, possuía baixa competência de transporte.
A ocorrência de camadas espessas de sedimentos finos, bem como presença de estratos com quantidades elevadas de matéria orgânica, incluindo restos vegetais (Figuras 10a, $10 b$ e 10c), sugere-se que um meandro do rio neste local teria sido abandonado, favorecendo o desenvolvimento de vegetação permanente. Estrato arenoso em contato erosivo com as lamas do canal abandonado indica que o rio pode ter retomado posteriormente seu curso através da migração do canal principal (Figura 9a). 


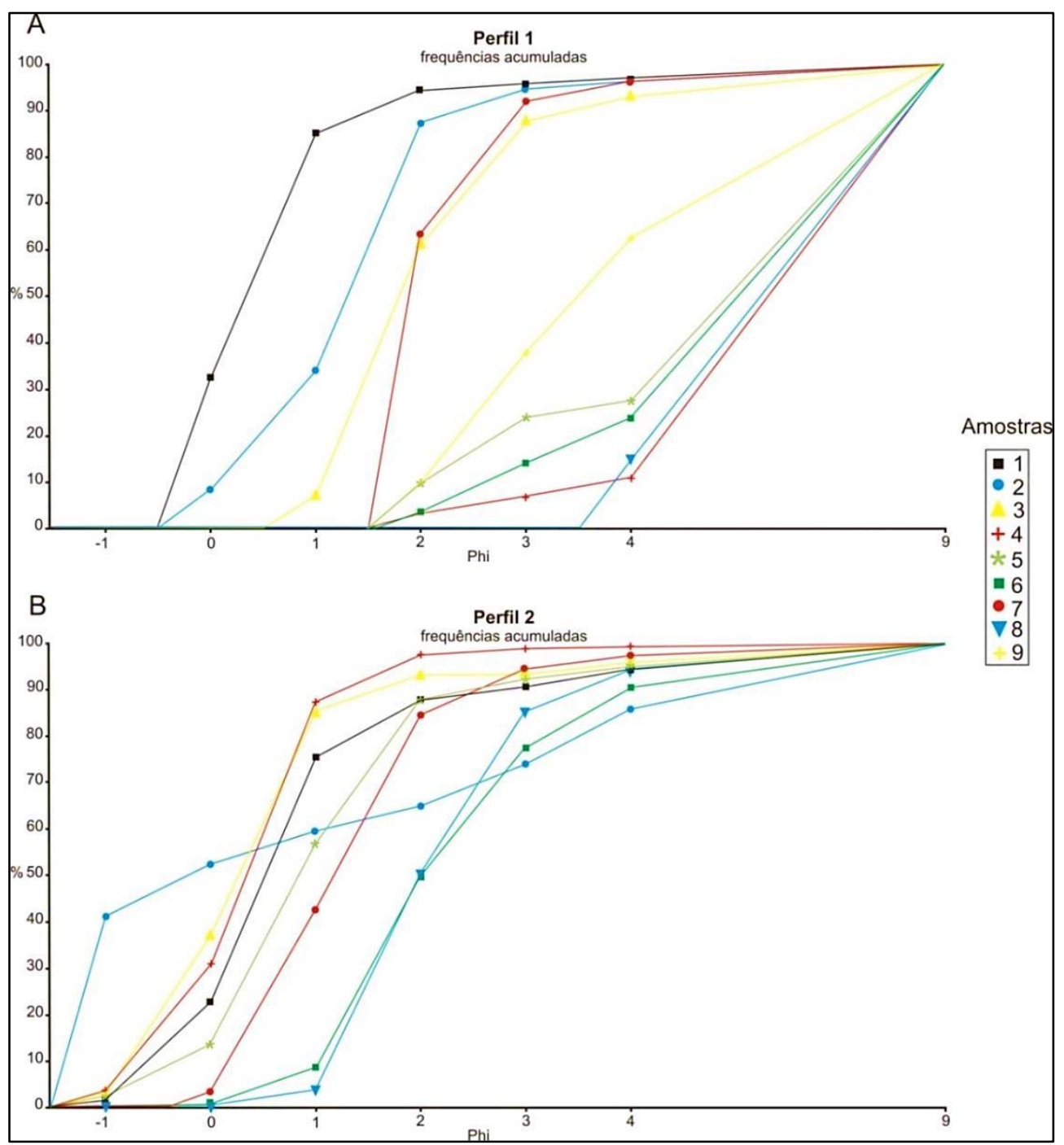

Figura 8 - Distribuição de frequências acumuladas de tamanhos de grãos nas amostras do perfil 1 (A) e do perfil 2 (B).

0 perfil estratigráfico 2 revela uniformidade na distribuição de classes de sedimentos ao longo da seção (Figuras 4b, 8b e 9b), porém mostra ainda baixa seleção granulométrica. Diante destas características e de acordo com as curvas de distribuição predominantes neste ponto (assimetria positiva), é possível afirmar que os momentos de deposição são dominantes (DUANE, 1964).
A mistura de diferentes classes granulométricas no perfil também reforça a hipótese de que houve uma diminuição na capacidade de transporte neste ponto. Tais características, associadas à composição heterogênea do arcabouço sedimentar deste perfil, permitem interpretar este conjunto como depósito colúvio-aluvial (Figura 9b). 


\section{ANÁLISE SEDIMENTAR E GEOMORFOLÓGICA PARA COMPREENSÃO DA DINÂMICA FLUVIAL LOCAL EM AMBIENTE DE PLANÍCIE COSTEIRA NA REGIÃO NORTE DE SANTA CATARINA}

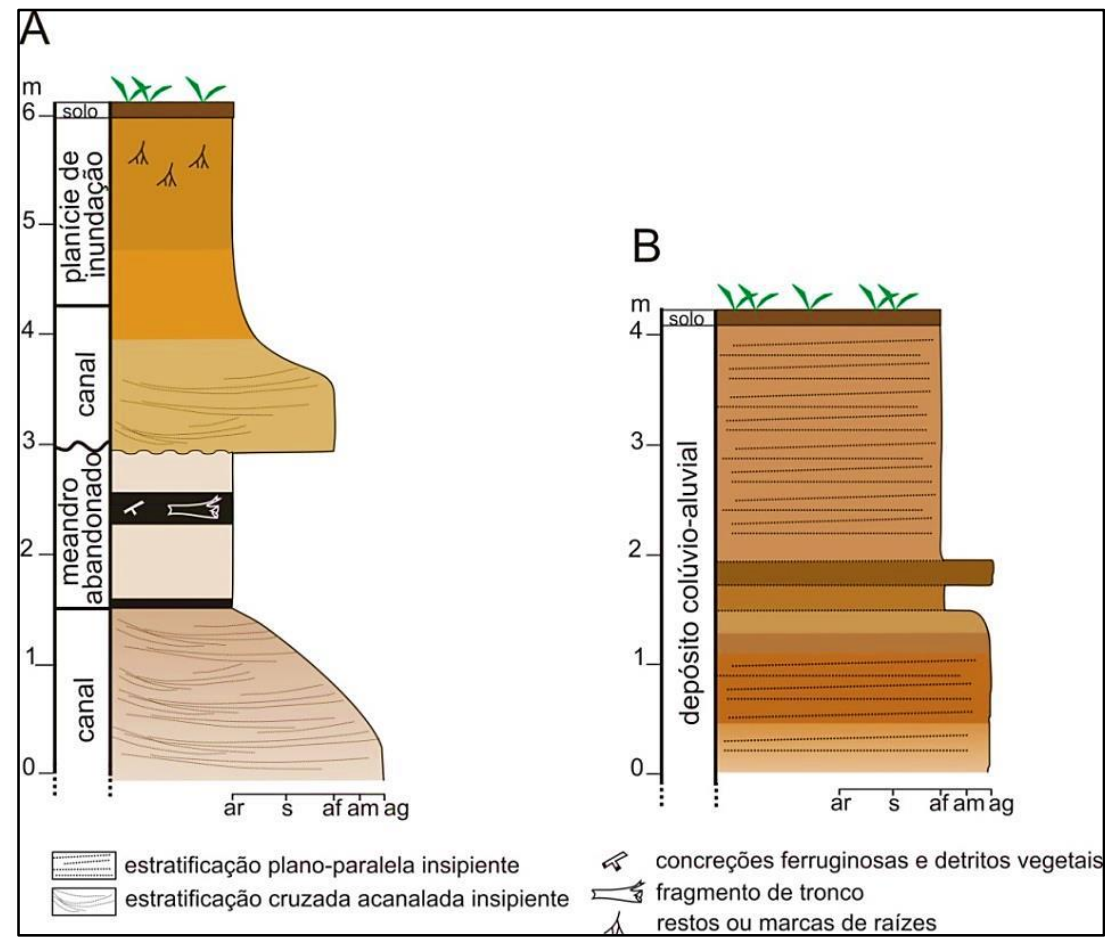

Figura 9 - Perfis estratigráficos e interpretação dos ambientes de deposição nos pontos 1 (A) e 2 (B)

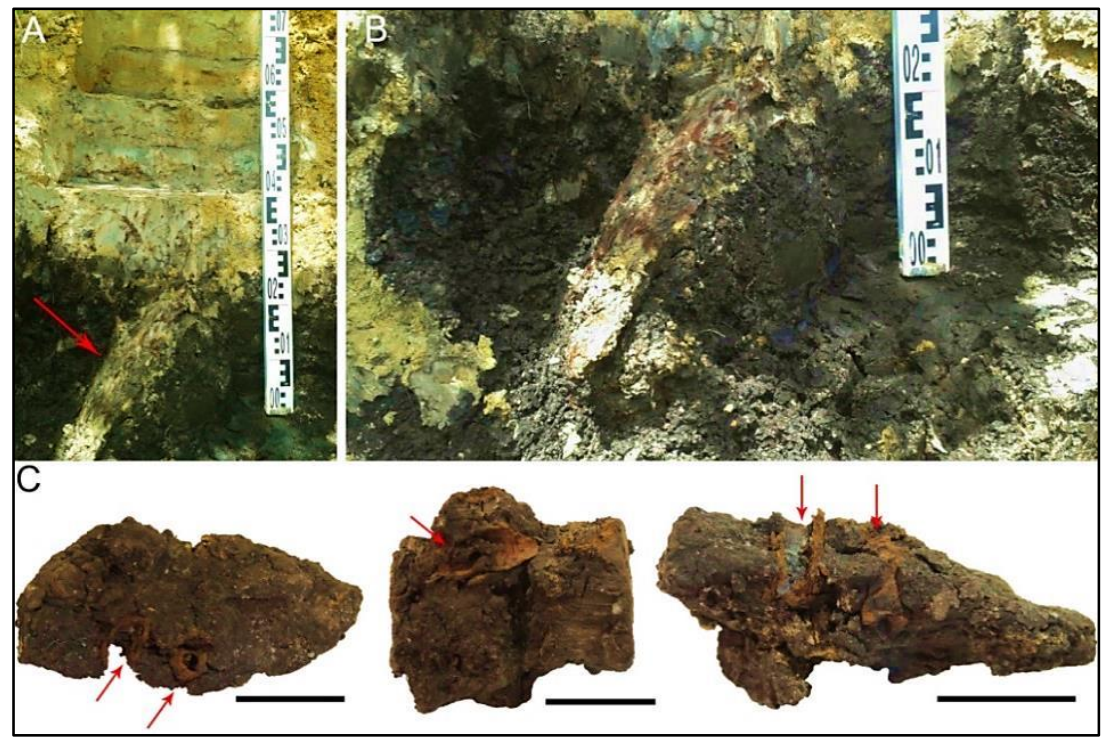

Figura 10 - Fragmentos vegetais no perfil 1: (A) Fragmento de tronco (seta vermelha) e (B) detalhe; (C) detritos vegetais (setas vermelhas) encontrados em associação com o fragmento de tronco.

Considerando as características texturais e granulométricas dos dois pontos estudados, verifica-se que o rio Três Barras possui uma dinâmica natural intrínseca a sua história deposicional (Figura 9). Entretanto, tais características podem contribuir, em associação com as intervenções antrópicas, com a intensificação de processos morfogenéticos que podem alterar a configuração do canal fluvial.

Com o aumento da energia de fluxo hídrico devido à canalização do rio (KELLER, 1978) à montante, somado a eventos pluviométricos esporádicos mais intensos, o canal ajusta suas dimensões através da erosão e deposição. Summerfield (1991) destaca que o aumento da 


\section{ANÁLISE SEDIMENTAR E GEOMORFOLÓGICA PARA COMPREENSÃO DA DINÂMICA FLUVIAL LOCAL EM AMBIENTE DE PLANÍCIE COSTEIRA NA REGIÃO NORTE DE SANTA CATARINA}

vazão em canais em que predominam as granulometrias finas no leito e margens, verificase o aumento da profundidade, enquanto que em canais com granulometrias mais grossas ocorre alargamento do canal com erosão das margens.

O caráter friável dos sedimentos das margens estudadas do rio Três Barras, bem como suas características granulométricas, favorecem a erosão das margens e posterior deposição no leito fluvial devido à baixa competência ao transporte em proximidade com sua foz, resultando no assoreamento do canal. Eventos naturais associados às atividades antrópicas observadas no trecho analisado podem ter favorecido alterações significativas no traçado do canal fluvial, como bem ilustra a Figura 11, cujas imagens demonstram a mudança do curso hídrico entre o final da década de 1980 e a década atual, a partir da implantação de um canal de drenagem em áreas de agricultura.

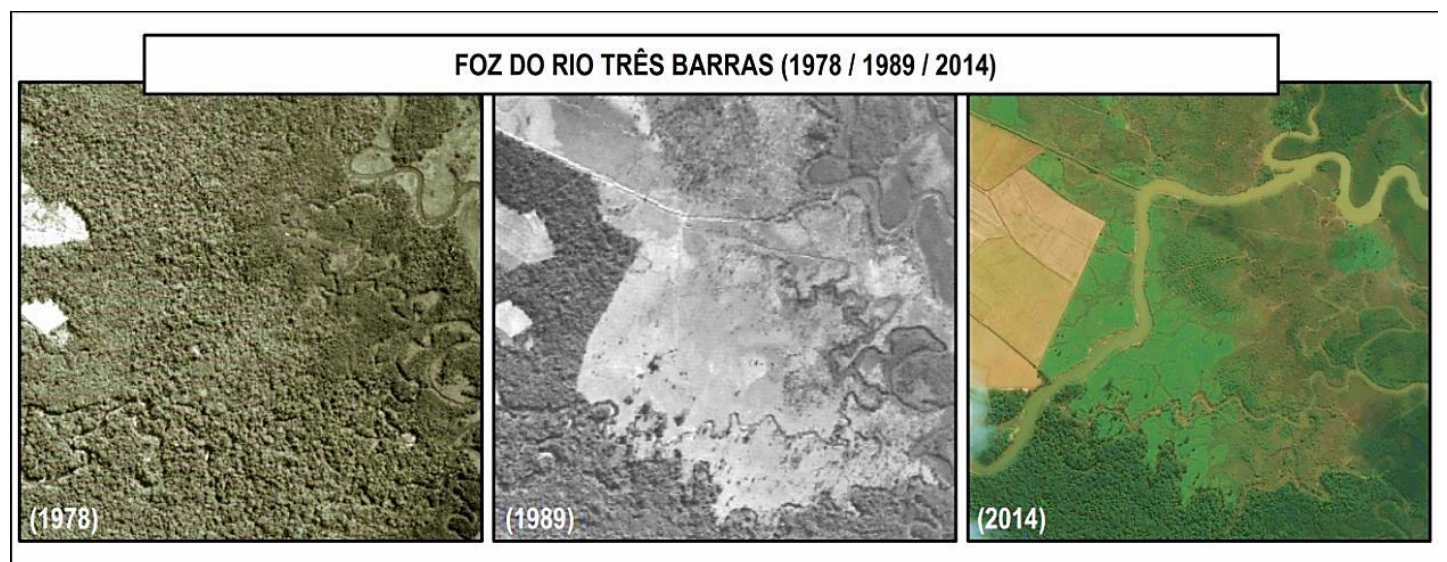

Figura 11 - Reconformação do traçado do canal fluvial à foz do rio Três Barras.

\section{CONSIDERAÇÕES FINAIS}

Neste estudo foi possível realizar uma caracterização estratigráfica a partir da análise da arquitetura sedimentar em um trecho do rio Três Barras no município de Garuva (SC), com o intuito de fornecer dados para a compreensão fluvial local da planície costeira do norte de Santa Catarina.

À montante da área de estudo observase intercalação de camadas com granulometrias mais grossas e finas, sugerindo ciclicidade na intensidade de transporte sedimentar neste local. A superposição de estratos com predominância de areias mais grossas sobre argilas com quantidades elevadas de matéria orgânica sugere a reativação de canais que soterraram uma possível antiga planície de inundação.

Em direção à jusante, a uniformidade de estratos com partículas grossas e baixa seleção granulométrica, somados às características das curvas de distribuição granulométrica, sugerem predomínio de eventos de deposição. O depósito neste local é interpretado como colúvio-aluvial.
A variação da assinatura granulométrica ao longo das margens do rio Três Barras, tanto vertical como horizontalmente, demonstrou que a dinâmica fluvial pode estar relacionada com ciclicidade de eventos de maior e menor energia. Esses fatores que regem a dinâmica fluvial local e que possuem grande influência na dinâmica fluvial natural, atualmente são intensificados por intervenções antrópicas significativas. Esta condição impõe problemas à população local em função do efeito sinérgico entre a ocorrência de eventos pluviométricos extremos, alterações da energia do fluxo hídrico e sua descarga líquida, decorrente da implantação de estruturas artificiais, retirada de material e alteração da paisagem.

\section{AGRADECIMENTOS}

Os autores agradecem à CAPES e ao Programa de Pós-Graduação Stricto Sensu em Geografia da Universidade Federal do Paraná pelo apoio financeiro. Ao Laboratório de Biogeografia e Solos - LABS pelo acesso ao 


\section{ANÁLISE SEDIMENTAR E GEOMORFOLÓGICA PARA COMPREENSÃO DA DINÂMICA FLUVIAL LOCAL EM AMBIENTE DE PLANÍCIE COSTEIRA NA REGIÃO NORTE DE SANTA CATARINA}

granulômetro a laser, ao Laboratório de Estudos Sedimentológicos - LabESed pelo acesso às instalações e ao técnico Daniel Cesar Antunes Paredes pelo auxílio nas análises granulométricas. Agradecimentos ainda aos três revisores anônimos pelas sugestões ao manuscrito e a Claudinei Taborda da Silveira pelo convite à participação neste volume especial da revista.

\section{REFERÊNCIAS}

ASSOCIAÇÃO BRASILEIRA DE NORMAS TÉCNICAS. ABNT. NBR 7181. Solo - Análise granulométrica. 1984. $13 p$

CAMARGO, M.G. 1999. Software para análise granulométrica SysGran, versão 3.0, Curitiba, UFPR. Disponível em www.cem.ufpr.br/sysgran. Acesso em 11/04/2016.

CAMARGO, M.G. SYSGRAN: um sistema de código aberto para análises granulométricas do sedimento. Revista Brasileira de Geociências, v. 36, n. 2, p. 371-378, 2006.

CHRISTOFOLETTI, A. Geomorfologia. 2a ed. Edgar Blucher, São Paulo, 1980.

CHRISTOFOLETTI, A. Geomorfologia fluvial. Edgard Blucher, São Paulo, 1981.

DOEGLAS, D.J. Interpretation of the results of mechanical analysis. Journal of Sedimentary Petrology, v. 16, n. 1, p. 19-40, 1946.

DUANE, D. Significance of skewness in recent sediments, Western Pamlico Sound, North Carolina. Journal of Sedimentary Petrology, v. 34, n. 4, p. 864-874, 1964.

FOLK, R.L.; WARD, W.C. Brazos river bar: a study in the significance of grain size parameters.
Journal of Sedimentary Petrology, v. 27, n. 1, p. 3-26, 1957.

FRIEDMAN, G. M. Distinction between dune, beach, and river sands from their textural characteristics. Journal of Sedimentary Petrology, v. 31, n. 4, p. 514-529, 1961.

KELLER, E. A. Pools, riffles and channelization. Environmental Geology, v. 2, n. 2. p. 119- 127, 1978.

KRUMBEIN, W.C. Size frequency distributions of sediments. Journal of Sedimentary Petrology, v. 4, n. 2, p. 65-77, 1934.

MARÇAL, M.S. Análise das mudanças morfológicas em seções transversais ao rio Macaé/RJ. Revista Brasileira de Geomorfologia, v. 14, n. 1, p. 59-68, 2013.

MARTINS, L.R. Recent Sediments and Grain size analysis. Revista Gravel, Porto Alegre, 2003. n. 1, p. 90-105, 2003.

SCHERER, C.M.S. Ambientes Fluviais. In: PEDREIRA, A. J. C. L.; ARAGÃO, M. A. N. F.; MAGALHÃES, A. J. C. Ambientes de Sedimentação Siliciclástica do Brasil. São Paulo: Beca-BALL Edições, 2008. p. 103-130. 2008.

SCHUMM, S.A.; STEVENS, M.A. Abrasion in place: A mechanism for rounding and size reduction of coarse sediments in rivers, Geology, v. 1, n. 1, p. 37-40, 1973.

SPENCER, D.W. The interpretation of grain size distribution curves of clastic sediments. Journal of Sedimentary Petrology, v. 33., n. 1, p. 180190, 1963.

SUGUIO, K. Geologia Sedimentar. Edgard Blucher, São Paulo, 2003.

SUMMERFIE LD, M. Global Geomorphology. John Wiley \& Sons. New York, 1991, 245 p. 